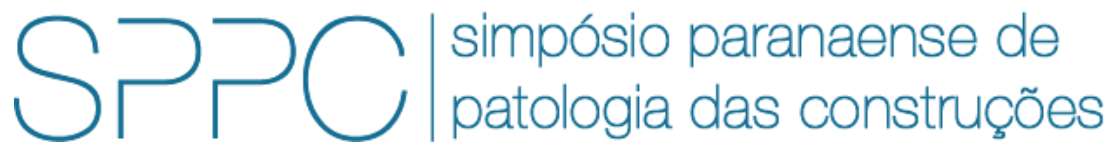

ISSN 2526-7248 artigo 2SPPC1032, pp. 380-391, 2017

\title{
Influência na resistência à tração na flexão de peças de concreto reforçadas com fibras de carbono revestidas de argamassa refratária submetidas à temperatura de $200^{\circ} \mathrm{C}$
}

\author{
MUNIZ, Natalia'; OLEINIK, Louise²; ROSSOT, Francyelli3; DE LUCA, Luis César ${ }^{4}$ \\ ${ }_{1}^{1}$ Natalia Muniz, Universidade Positivo, natalia.rm@hotmail.com \\ 2 Louise Oleinik, Universidade Positivo, oleiniklouise@hotmail.com \\ 3 Francyelli Rossot, Universidade Positivo, fran_rossot@hotmail.com \\ ${ }^{4}$ Luis César Siqueira De Luca, Grupo IDD, deluca@idd.com.br
}

Resumo: O reforço estrutural com Polímero Reforçado com Fibra de Carbono (PRFC) é constituído de um sistema de fibra de carbono e adesivo epoxídico e, quando esses são expostos a grandes temperaturas, sofrem o desprendimento da cola epóxi, o material epoxídico perde sua eficiência, surgindo assim a necessidade de proteção do reforço estrutural. O custo com a proteção do reforço estrutural é viável se comparado com o custo já utilizado para a reparação da estrutura, garantindo maior durabilidade. No sistema PRFC a aplicação da argamassa refratária é a responsável pelo retardo do colapso da estrutura e, além disso, o sistema possui poucas perdas, sendo adaptável a diferentes tipos de projetos e formas. O presente artigo objetivou demonstrar a influência de diferentes espessuras de revestimentos de argamassa refratária na resistência à tração na flexão de peças de concreto reforçadas com PRFC, submetidas à temperatura de $200^{\circ} \mathrm{C}$. Assim, realizou-se um programa experimental, que consistiu na produção de corpos de prova prismáticos de concreto reforçados com fibra de carbono, revestidos de argamassa refratária em três diferentes espessuras, sendo $10 \mathrm{~mm}$, $15 \mathrm{~mm}$ e $20 \mathrm{~mm}$. Posteriormente, foram expostos à temperatura de $200^{\circ} \mathrm{C}$ durante 24 horas e, solicitados em uma prensa hidráulica para realização do ensaio à tração na flexão. Observou-se que a espessura de $15 \mathrm{~mm}$ obteve ganhos médios de resistência maiores que as espessuras de $10 \mathrm{~mm}$ e $20 \mathrm{~mm}$, quando comparadas aos valores médios das peças de referência, sendo um ganho de $74 \%$ de resistência. Conclui-se que a espessura do revestimento influenciou na resistência a tração na flexão.

Palavras-chave: PRFC; Fibra de carbono; Argamassa refratária.

Abstract: The reinforcement with Carbon Fiber Reinforced Polymer (CFRP) consists of a carbon fiber and epoxy adhesive system and, when exposed to high temperatures, epoxy glue is released, the epoxy material loses its efficiency. Therefore the need for structural reinforcement protection. The cost with the protection of the structural reinforcement is feasible, if compared with the cost already used for the repair of the structure, guaranteeing longer durability. In the CFRP system the application of the refractory mortar is responsible for the delay of the collapse of the structure and, in addition, the system has few losses, being adaptable to different types of projects and forms. The present article aimed to demonstrate the influence of different thicknesses of refractory mortar coatings on the flexural tensile strength of reinforced CFRP concrete parts submitted to a temperature of $200^{\circ} \mathrm{C}$. Therefore, an experimental program was carried out, which consisted in the production of prismatic concrete specimens reinforced with carbon fiber, coated with refractory mortar in three different thicknesses, being $10 \mathrm{~mm}, 15 \mathrm{~mm}$ and $20 \mathrm{~mm}$. Subsequently, they were exposed to a temperature of $200^{\circ} \mathrm{C}$ during 24 hours and then requested in a hydraulic press to carry out the flexural traction test. It was observed that the thickness of $15 \mathrm{~mm}$ obtained average gains of resistance bigger than the thicknesses of $10 \mathrm{~mm}$ and $20 \mathrm{~mm}$, when compared to the average values of the reference pieces, being a gain of $74 \%$ of resistance. It was concluded that the thickness of the coating influenced the flexural tensile strength.

Keywords: CFRP; Carbon fiber; Refractory mortar. 


\section{Introdução} 2SPPC1032, pp. 380-391, 2017. DOI: 10.4322/2SPPC.2017.032

A temática principal apresentada neste artigo é o estudo da influência na resistência da tração na flexão de peças de concreto reforçadas com Polímero Reforçado com Fibra de Carbono (PRFC), revestidas com diferentes espessuras de argamassa refratária submetidas à temperatura de $200^{\circ} \mathrm{C}$.

O reforço de estruturas de concreto, com compósitos de fibras de carbono, se destaca como alternativa de reforço. Suas propriedades mecânicas semelhantes às do aço, e sua dureza, tem uma grande resistência ao impacto [2-5]. Segundo Fortes [4], as características que mais se destacam no reforço estrutural por meio da colagem externa de materiais PRFC são o baixo peso, alta resistência à tração, alta rigidez, facilidade de aplicação e a possibilidade da utilização da estrutura 48 horas após a aplicação.

Entretanto, existe uma preocupação referente aos compósitos à base de matriz epóxi, utilizados na colagem da fibra de carbono e, por consequência do seu comportamento de redução da resistência do material com o aumento de temperatura. Os mesmos são prejudicados após atingirem a temperatura de $70^{\circ} \mathrm{C}$ [4]. Desperdiçando a resistência da fibra de carbono que pode resistir até $1.000^{\circ} \mathrm{C}$ [2].

Com o intuito de viabilizar termicamente o reforço estrutural por PRFC, identificou-se que a argamassa refratária pode ser um recurso à proteção dessa fibra de carbono por meio de uma camada de revestimento. Apresentando características interessantes de trabalhabilidade, plasticidade, deformabilidade, capacidade de retenção de água e a capacidade de suportar altas temperaturas além da simplicidade de aplicação, a argamassa refratária não exige mão de obra especializada. Sua composição por agregados minerais e aditivos especiais desperta a alternativa de utilização para proteção do reforço estrutural em casos de incêndios [3].

Esperava-se que quanto maior fosse a espessura de argamassa aplicada para proteção do PRFC, a resistência do sistema aumentasse, pois, o isolamento térmico feito pela argamassa refratária protegeria a cola epóxi, o que garantindo menor perda das propriedades do material.

Utilizou-se um programa experimental que considera a aplicação de três espessuras de argamassa, buscando verificar a influência do revestimento refratário no sistema.

\section{Programa experimental}

A Figura 1 esclarece as etapas e passos realizados no programa experiental. 
MUNIZ, M.R.N; ET AL., VERIFICAÇÃO DA INFLUÊNCIA NA RESISTÊNCIA À TRAÇÃO NA FLEXÃO DE DIFERENTES ESPESSURAS DE REVESTIMENTO DE ARGAMASSA REFRATÁRIA EM PEÇAS DE CONCRETO REFORÇADO COM FIBRAS DE CARBONO SUBMETIDAS À TEMPERATURA DE $200^{\circ} \mathrm{C}$. $2^{\circ}$ Simpósio Paranaense de Patologia das Construções (2० SPPC), artigo 2SPPC1032, pp. 380-391, 2017. DOI: 10.4322/2SPPC.2017.032

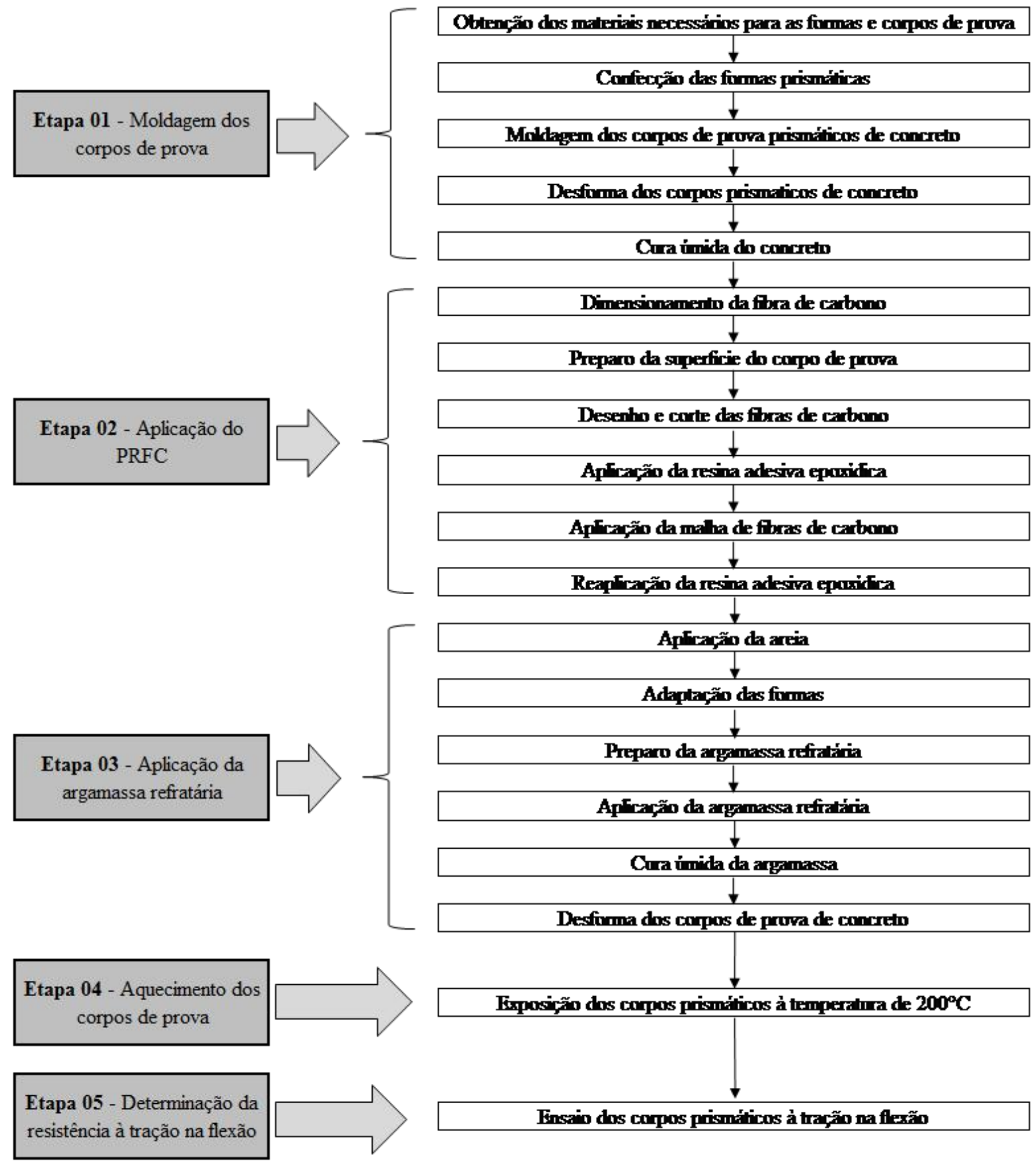

Figura 1: Programa Experiental. Fonte: do Autor, 2016

\subsection{Primeira Etapa - Moldagem dos Corpos de Prova}

Foram realizados 5 passos dentro da primeira etapa. Iniciou-se obtendo os materiais necessários para o programa experimental, até a cura do substrato de concreto, sendo elas:

\subsubsection{Obtenção do material necessário para as formas e os corpos de prova}

Durante este passo foi adquirido o madeirite com cola fenólica, e o concreto para a confecção das formas e dos corpos de prova prismáticos. 
MUNIZ, M.R.N; ET AL., VERIFICAÇÃO DA INFLUÊNCIA NA RESISTÊNCIA À TRAÇÃO NA FLEXÃO DE DIFERENTES ESPESSURAS DE REVESTIMENTO DE ARGAMASSA REFRATÁRIA EM PEÇAS DE CONCRETO REFORÇADO COM FIBRAS DE CARBONO SUBMETIDAS À TEMPERATURA DE $200^{\circ} \mathrm{C}$. $2^{\circ}$ Simpósio Paranaense de Patologia das Construções ( $\left.2^{\circ} \mathrm{SPPC}\right)$, artigo

\subsubsection{Confecção das formas prismáticas} 2SPPC1032, pp. 380-391, 2017. DOI: 10.4322/2SPPC.2017.032

Neste passo foi realizada a marcação das dimensões, os cortes no material e a montagem das peças. Ilustrado na Figura 2.

\subsubsection{Moldagem dos porpos de prova prismáticos}

$\mathrm{O}$ traço do concreto utilizado foi calculado para atingir $35 \mathrm{MPa}$ de resistência à compressão aos 28 dias e obter um abatimento a fim de facilitar o processo $(1 ; 3 ; 3,5$; $0,655 ; 0,15)$. Os corpos de prova prismáticos de concreto foram moldados com dimensões de $45 \mathrm{~cm} \times 10 \mathrm{~cm} \times 10 \mathrm{~cm}$. O adensamento foi realizado obedecendo a NBR 5738 [1], que recomenda que corpos de prova prismáticos com dimensão básica de $100 \mathrm{~mm}$ sejam moldados com uma camada e 75 golpes distribuídos uniformemente em toda sua camada transversal para um adensamento manual. Foi colocado sob os corpos de prova prismáticos uma camada de papel plastico, previnindo a perda de umidade por calor exessivo. Demonstrado na Figura 2.

\subsubsection{Desforma dos corpos de prova de concreto}

Os corpos de prova prismáticos foram deixados em repouso e desformados 48 horas após a moldagem, possibilitando assim, que atingissem suficiente resistência para que a desforma fosse realizada sem prejudicar suas características geométricas e mecânicas.

\subsubsection{Cura umida do concreto}

A cura foi realizada em um tanque de água saturada de cal. Silva, [6] realizou um estudo sobre a influência do tipo de cura na resistência à compressão e constatou que com o tanque saturado de cal, a resistência a compressão chega o mais perto do ideal se comparado a outros métodos de cura.

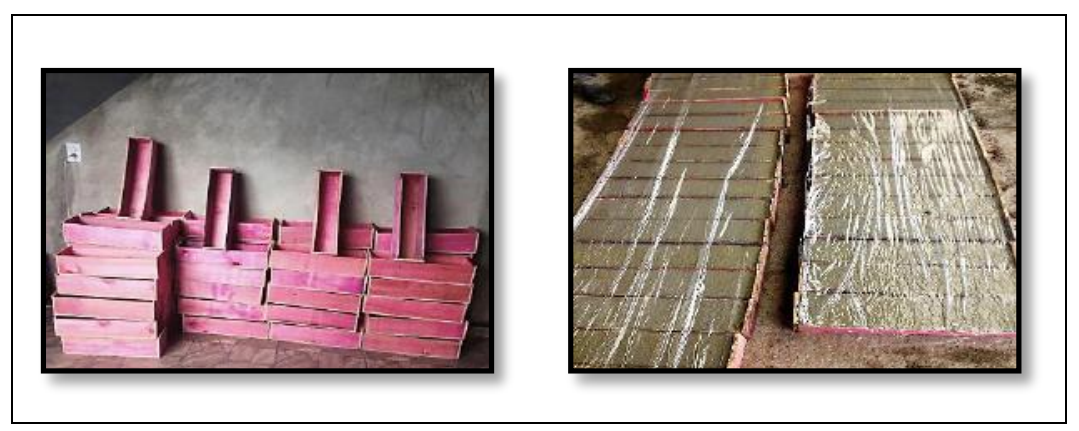

Figura 2: Passos 2.1.2 e 2.1.3

\subsection{Segunda Etapa - Aplicação de PRFC}

Para realização do reforço estrutural com fibras de carbono, foi utilizado, como apoio, o Manual de Reforço das Estruturas de Concreto Armado com Fibras de Carbono, desenvolvido por Machado [5] e a ficha técnica do produto Viapoxi Adesivo Gel.

O Viapo|® Carbon é um sistema de reforço estrutural, constituído de resinas e fibra de carbono. Esse sistema foi doado pela Viapol Euclide Group, empresa patrocinadora deste trabalho. Sistema composto por: 
MUNIZ, M.R.N; ET AL., VERIFICAÇÃO DA INFLUÊNCIA NA RESISTÊNCIA À TRAÇÃO NA FLEXÃO DE DIFERENTES ESPESSURAS DE REVESTIMENTO DE ARGAMASSA REFRATÁRIA EM PEÇAS DE CONCRETO REFORÇADO COM FIBRAS DE CARBONO SUBMETIDAS À TEMPERATURA DE $200^{\circ} \mathrm{C}$. $2^{\circ}$ Simpósio Paranaense de Patologia das Construções ( $2^{\circ} \mathrm{SPPC}$ ), artigo 2SPPC1032, pp. 380-391, 2017. DOI: 10.4322/2SPPC.2017.032

- $\quad$ Viapolß Carbon CFW300: Manta de fibra de carbono que apresenta, conforme especificações do fabricante, uma espessura de $0,165 \mathrm{~mm}$, uma resistência máxima a tração de $4900 \mathrm{MPa}$, módulo de elasticidade de 230 GPa e uma gramatura de $300 \mathrm{~g} / \mathrm{m}^{2}$.

- Viapoxi AdesivoGel: Adesivo à base de resina epóxi, bi componente de elevada fluidez e isento de solventes. Foi utilizado para colagem da manta nos prismas de concreto. Ele apresenta segundo o fornecedor, uma resistência a compressão de até $75 \mathrm{MPa}$, massa específica de $1,92 \mathrm{~g} / \mathrm{cm}^{3}$ e tempo de trabalhabilidade de 60 a 90 minutos.

\subsubsection{Dimensionamento da fibra de carbono}

Para garantir que a prensa utilizada atingisse a resistência necessária para o rompimento do corpo de prova prismático, foi realizado o dimensionamento da área transversal de fibra de carbono necessária, para que ocorresse o rompimento com aproximadamente 50tf com base em Machado [5] e ACI COMMITTEE 440 [7]. Para que fosse possivel o dimensionamento, foi necessário adaptações, pois os materiais existentes são para dimensioamento de concreto armado e não concreto simples.

A Figura 3 apresenta o esquema de cargas aplicadas contendo [A] ilustração da aplicação de cargas da figura, [B] o diagrama de esforços cortantes e [C] o diagrama de momentos fletores relativos a carga máxima a ser plicada.

Como se considerou o corpo de prova sem o reforço de aço para resistir aos esforços de tração, os cálculos apresentados a seguir foram efetuados para que o composto PRFC resistisse a estes esforços e não apenas atuasse como reforço da estrutura.

\subsubsection{Preparo da superfície do corpo de prova}

Escolheu-se a superfície com maior atrito para aplicação da fibra, com intuito de garantir a melhor aderência possível das interfaces. Primeiramente houve a aplicação do primer da Viapol na superfície seca e esperou-se duas horas até que fosse correto aplicar a resina epoxídica, como indica o fabricante.

\subsubsection{Desenho e corte das fibras de carbono.}

Durante este período de espera de duas horas, foi realizada a marcação e os cortes da fibra de carbono CW300. O corte dos pedaços de fibra de carbono nas dimensões de $7 \mathrm{~cm} \times 20 \mathrm{~cm}$ com $0,165 \mathrm{~cm}$ de espessura foi dimensionado conforme informado no 2.2.1.

\subsubsection{Aplicação da resina adesiva epoxídica}

Realizou-se a aplicação de uma camada de resina epoxídica Viapoxi Adesivo Gel com função de colar a fibra de carbono ao substrato e transferir as tensões aplicadas no corpo de prova prismático para a malha de fibra de carbono. 
MUNIZ, M.R.N; ET AL., VERIFICAÇÃO DA INFLUÊNCIA NA RESISTÊNCIA À TRAÇÃO NA FLEXÃO DE DIFERENTES ESPESSURAS DE REVESTIMENTO DE ARGAMASSA REFRATÁRIA EM PEÇAS DE CONCRETO REFORÇADO COM FIBRAS DE CARBONO SUBMETIDAS À TEMPERATURA DE $200^{\circ} \mathrm{C}$. $2^{\circ}$ Simpósio Paranaense de Patologia das Construções ( $2^{\circ} \mathrm{SPPC}$ ), artigo

2.2.5 Aplicação da malha de fibras de carbono 2SPPC1032, pp. 380-391, 2017. DOI: 10.4322/2SPPC.2017.032

Com demarcações feitas nos prismas de concreto, foi aplicado o tecido de fibra de carbono. Utilizou-se um pequeno rolo para aplicar uma pequena pressão sobre a fibra já colocada na face do prisma, a fim de melhorar a aderência entre as camadas.

\subsubsection{Reaplicação de resina adesiva epoxídica}

Foi aplicada uma nova camada de resina adesiva epoxídica para garantir uma melhor aderência entre o concreto e a fibra, formando assim o PRFC.

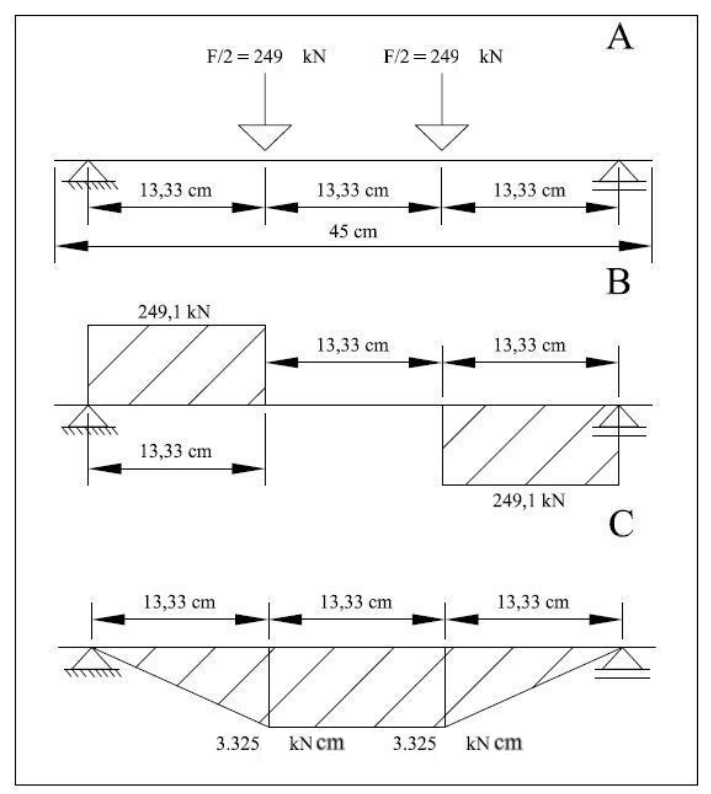

Figura 3: Esquema de cargas aplicadas. Fonte: do Autor, 2016.

Abaixo a Figura 4 apresenta ilustrações das etapas descritas acima.
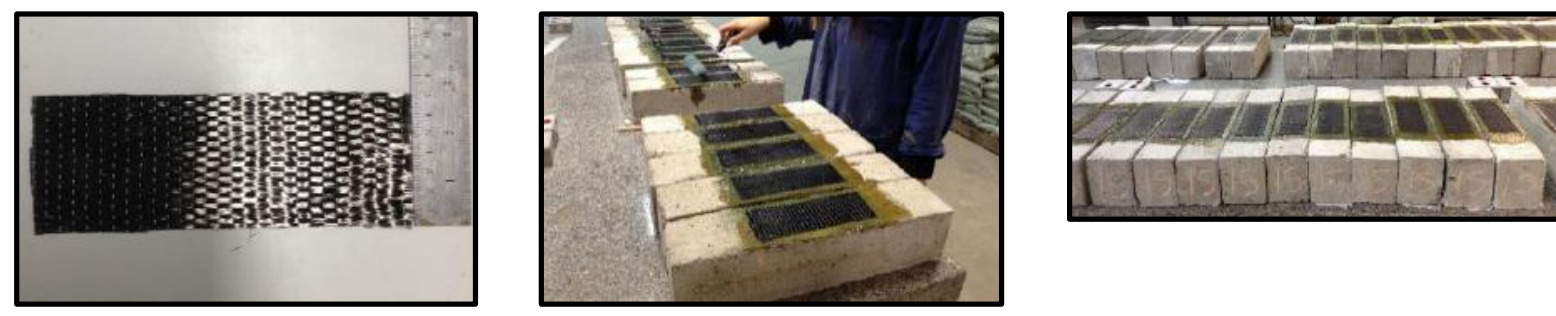

Figura 4: Passos 2.2.3 2.2.4 e 2.2.5 respectivamente. Fonte: do Autor, 2016 
MUNIZ, M.R.N; ET AL., VERIFICAÇÃO DA INFLUÊNCIA NA RESISTÊNCIA À TRAÇÃO NA FLEXÃO DE DIFERENTES ESPESSURAS DE REVESTIMENTO DE ARGAMASSA REFRATÁRIA EM PEÇAS DE CONCRETO REFORÇADO COM FIBRAS DE CARBONO SUBMETIDAS À TEMPERATURA DE $200^{\circ} \mathrm{C}$. $2^{\circ}$ Simpósio Paranaense de Patologia das Construções ( $\left.2^{\circ} \mathrm{SPPC}\right)$, artigo

\subsection{Terceira Etapa - Aplicação da argamassa refratária} 2SPPC1032, pp. 380-391, 2017. DOI: 10.4322/2SPPC.2017.032

Esta etapa trata da aplicação da argamassa refratária na superfície que contém a fibra de carbono aplicada.

\subsubsection{Aplicação de areia}

Aplicou-se uma pequena camada de areia com o intuito de melhorar a aderência entre a resina e a argamassa que seria posteriormente aplicada. Esta aplicação ocorreu imediatamente após a etapa 2.2.6.

\subsubsection{Adaptação das formas}

Para garantir a aplicação da argamassa refratária com a espessura especificada, foi realizada uma modificação nas formas, garantindo assim a confiabilidade da espessura necessária.

A argamassa ensaiada foi a da empresa Siláqua preparada com o traço sugerido pelo fabricante, $1 ; 5 ; 2$.

\subsubsection{Aplicação da argamassa refratária}

Após a aplicação da areia, seu excesso foi retirado com o auxílio de um compressor de ar, para garantir que nenhuma partícula solta prejudicasse a aderência. Com o auxílio da forma, foi aplicada uma camada de argamassa de cada espessura em grupos de 15 corpos de prova na interface reforçada com fibra de carbono dos prismas de concreto.

\subsubsection{Cura úmida da argamassa}

Por orientação do fornecedor da argamassa, os corpos de provas prismáticos foram levados para a cura de 72 horas em câmara úmida.

\subsubsection{Desforma dos corpos de prova de concreto}

Após as 72 horas pré-determinadas, os corpos de prova foram retirados da câmara úmida e desformados. A Figura 5 apresenta passos da terceira etapa.
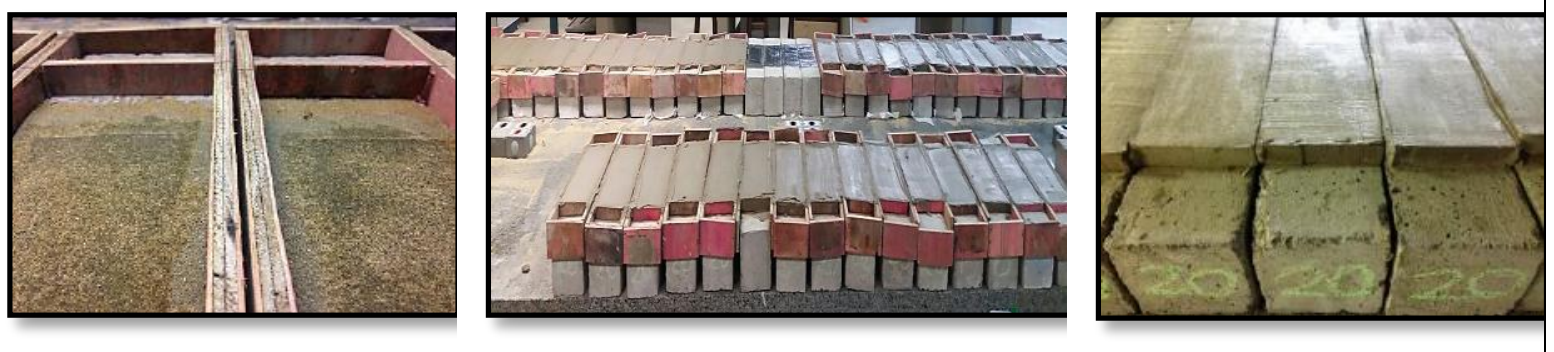

Figura 5: Passos 2.3.2, 2.3.3 e 2.3.5 respectivamente. Fonte: do Autor, 2016 
MUNIZ, M.R.N; ET AL., VERIFICAÇÃO DA INFLUÊNCIA NA RESISTÊNCIA À TRAÇÃO NA FLEXÃO DE DIFERENTES ESPESSURAS DE REVESTIMENTO DE ARGAMASSA REFRATÁRIA EM PEÇAS DE CONCRETO REFORÇADO COM FIBRAS DE CARBONO SUBMETIDAS À TEMPERATURA DE $200^{\circ} \mathrm{C}$. $2^{\circ}$ Simpósio Paranaense de Patologia das Construções ( $2^{\circ} \mathrm{SPPC}$ ), artigo

\subsection{Quarta Etapa - Exposição dos corpos prismáticos a temperatura de $200^{\circ} \mathbf{C}$}

O aquecimento das peças prismáticas de concreto foi uma das etapas principais do programa, pois através dela é simulado o calor provocado por um incêndio. Nesta etapa as peças de concreto foram colocadas na estufa sob uma temperatura de $200^{\circ} \mathrm{C}$ durante 24 horas. A Figura 6 comté alguns corpos de prova assim que colocados na estufa.

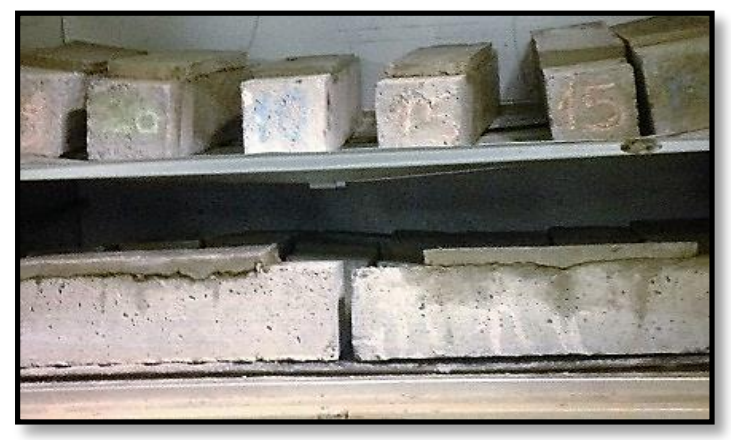

Figura 6: Corpos de prova prisáticos subetidos a $200^{\circ} \mathrm{C}$. Fonte: do Autor, 2016

\subsection{Quinta Etapa - Determinação da resistência}

Logo após a quarta etapa, as peças foram ensaiadas à tração na flexão. O ensaio foi realizado de acordo com a NBR 12142 (2010) com o intuito de observar a influência do calor na resistência à tração na flexão da peça reforçada com o PRFC revestida com argamassa refratária em relação a peça de referencial. A Figura 7 apresenta 0 corpo de aprova após ser ensaiado.

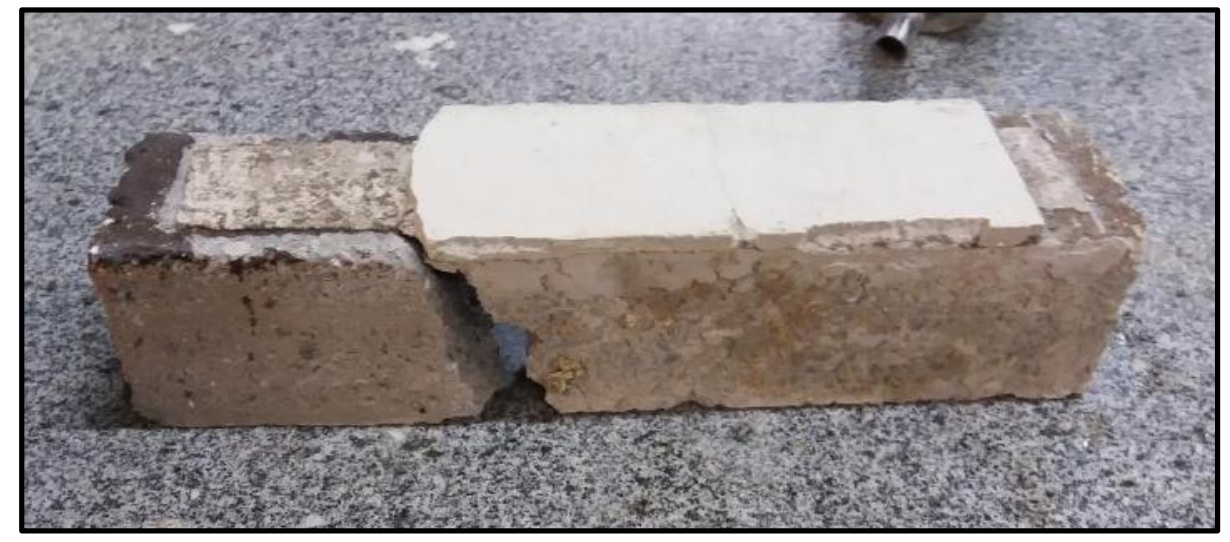

Figura 7: Corpo de prova prisatico após ropimento. Fonte: do Autor, 2016

\section{Analise dos resultados}

Os resultados apresentados e avaliados são referentes aos quarenta e cinco corpos de prova prismáticos de concreto revestidos com argamassa refratátia Siláqua com $10 \mathrm{~mm}, 15 \mathrm{~mm}$ e $20 \mathrm{~mm}$ de espessura e aos quinze corpos de prova prismáticos de concreto sem o revestimento. 
MUNIZ, M.R.N; ET AL., VERIFICAÇÃO DA INFLUÊNCIA NA RESISTÊNCIA À TRAÇÃO NA FLEXÃO DE DIFERENTES ESPESSURAS DE REVESTIMENTO DE ARGAMASSA REFRATÁRIA EM PEÇAS DE CONCRETO REFORÇADO COM FIBRAS DE CARBONO SUBMETIDAS À TEMPERATURA DE $200^{\circ} \mathrm{C}$. $2^{\circ}$ Simpósio Paranaense de Patologia das Construções ( $\left.2^{\circ} \mathrm{SPPC}\right)$, artigo 2SPPC1032, pp. 380-391, 2017. DOI: 10.4322/2SPPC.2017.032

Após todas as peças revestidas com revestimento de argamassa refratária e sem 0 revestimento serem submetidas a uma temperatura de $200^{\circ} \mathrm{C}$ por um período de 24 horas na estufa, elas foram ensaiadas em uma prensa hidráulica para realização do ensaio à tração na flexão.

A Tabela 1 apresenta os resultados por ordem crescente e análises realizadas na Quinta Etapa do programa experimental dos corpos de prova prismáticos com e sem revestimento da argamassa refratária Siláqua. Verifica-se a variação de resistência entre os quatro grupos de corpos de prova, mostrando os acréscimos médios na resistência dos prismas revestidos com argamassa refratária em relação aos prismas referenciais.

Tabela 1: Carga de ruptura x Corpos de prova prismáticos.

\begin{tabular}{|c|c|c|c|c|}
\cline { 2 - 5 } \multicolumn{1}{c|}{} & \multicolumn{4}{c|}{ Carga Máxima Aplicada [F] [kN] } \\
\hline $\mathbf{N}$ & Referência & $\begin{array}{c}\text { Argamassa } \\
\text { Espessura de 10 mm }\end{array}$ & $\begin{array}{c}\text { Argamassa } \\
\text { Espessura de 15 mm }\end{array}$ & $\begin{array}{c}\text { Argamassa } \\
\text { Espessura de 20 mm }\end{array}$ \\
\hline 1 & 4,37 & 12,89 & 13,57 & 9,37 \\
\hline 2 & 6,94 & 13,19 & 13,97 & 10,16 \\
\hline 3 & 7,39 & 13,88 & 14,18 & 10,19 \\
\hline 4 & 7,78 & 14,03 & 14,21 & 10,56 \\
\hline 5 & 8,21 & 14,34 & 14,64 & 10,57 \\
\hline 6 & 8,92 & 14,38 & 14,83 & 12,40 \\
\hline 7 & 9,30 & 14,44 & 15,53 & 12,50 \\
\hline 8 & 9,72 & 14,49 & 15,87 & 12,50 \\
\hline 9 & 9,88 & 14,82 & 16,67 & 12,71 \\
\hline 10 & 10,40 & 15,61 & 17,04 & 14,04 \\
\hline 11 & 10,56 & 15,73 & 17,94 & 15,63 \\
\hline 12 & 10,93 & 16,05 & 17,97 & 16,50 \\
\hline 13 & 10,98 & 17,15 & 19,59 & 17,43 \\
\hline 14 & 12,57 & 18,84 & 19,61 & 17,70 \\
\hline 15 & 13,05 & 19,62 & 20,00 & 12,8833 \\
\hline Média & 9,4000 & 15,2973 & 16,3747 & 2,7741 \\
\hline Desvio Padrão & 2,2450 & 1,9410 & 2,2198 & $22 \%$ \\
\hline Coeficiente de Variação (\%) & $24 \%$ & $13 \%$ & $14 \%$ & $37 \%$ \\
\hline Relação a Referência & - & $63 \%$ & $74 \%$ & \\
\hline & & & & \\
\hline Percentual em & & & & \\
\hline & & & & \\
\hline
\end{tabular}

Fonte: do Autor, 2016.

A Figura 8 apresenta a variação entre as resistências à tração na flexão dos corpos prismático de referência e os revestidos com argamassa. 
MUNIZ, M.R.N; ET AL., VERIFICAÇÃO DA INFLUÊNCIA NA RESISTÊNCIA À TRAÇÃO NA FLEXÃO DE DIFERENTES ESPESSURAS DE REVESTIMENTO DE ARGAMASSA REFRATÁRIA EM PEÇAS DE CONCRETO REFORÇADO COM FIBRAS DE CARBONO SUBMETIDAS À TEMPERATURA DE $200^{\circ} \mathrm{C}$. $2^{\circ}$ Simpósio Paranaense de Patologia das Construções ( $2^{\circ} \mathrm{SPPC}$ ), artigo 2SPPC1032, pp. 380-391, 2017. DOI: 10.4322/2SPPC.2017.032

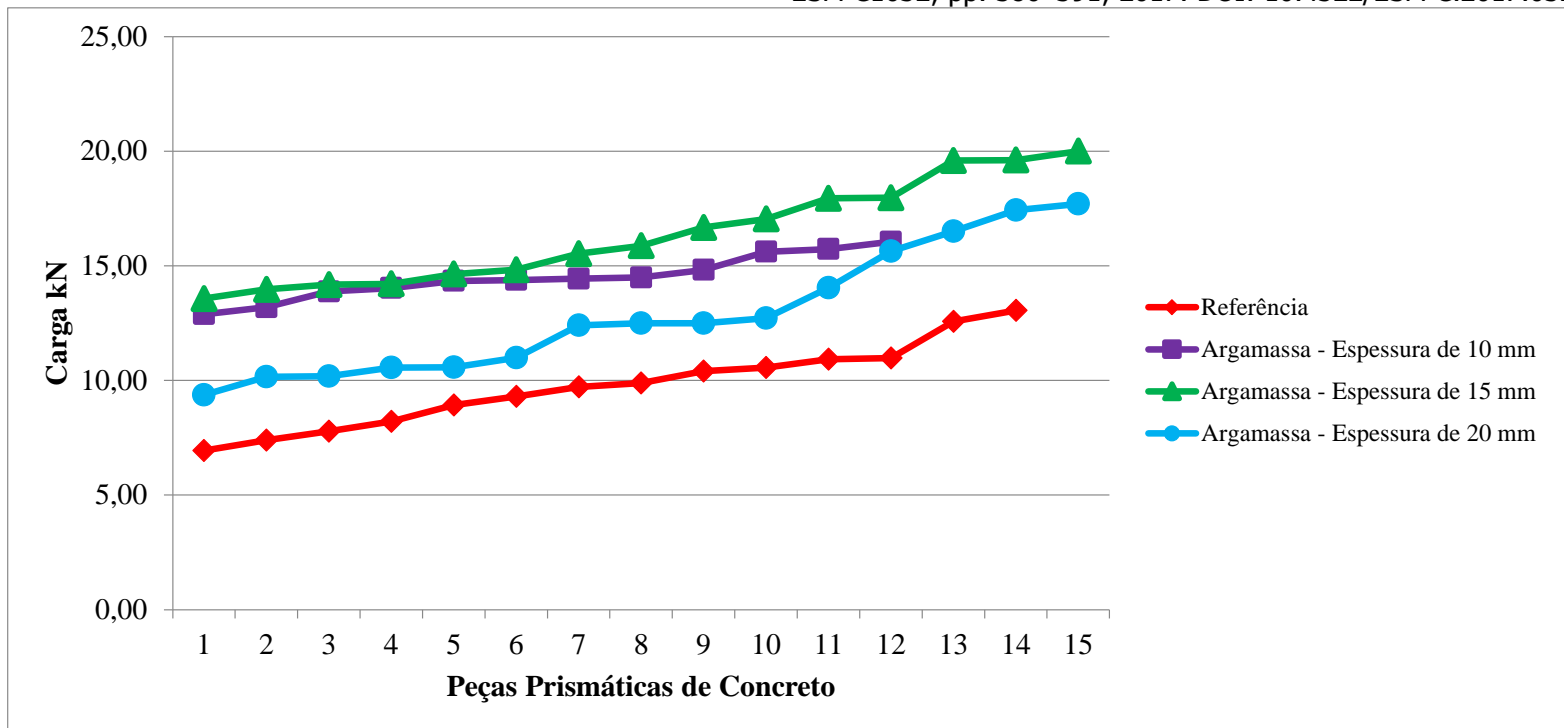

Figura 8: Força de ruptura x Corpos de prova prismáticos. Fonte: do Autor, 2016.

Pode-se observar que os três grupos de corpos de prova revestidos apresentaram proteção do reforço, portanto, os corpos prismáticos apresentaram um ganho resistência significativa em relação à média dos prismas referenciais, tendo $75,56 \%$ dos corpos prismáticos possuindo ganho.

Para que fosse possível analisar de forma consistente a variância dos dados, utilizouse a análise ANOVA, que testa a hipótese de que existe diferença significativa entre as médias dos rompimentos, e, se o fator espessura exerce influência no resultado. A hipótese nula afirma que todas as médias das amostras são iguais, enquanto a hipótese alternativa afirma que pelo menos uma é diferente, então se $F>F_{c r i ́ t i c o}$ e P $<0,05$ significa que os valores são significativos.

$\mathrm{Na}$ análise realizada foi determinado que a variação das espessuras do material propiciaria valores expressivos, esse fato fica evidente quando comparamos o valor de $\mathrm{F}$ com $F_{\text {crítico, }}$, obtendo nas três comparações valores maiores para $\mathrm{F}$, além disso, o valor de $P$ foi menor que 0,05 nos três casos. A Tabela 2 apresenta os resultados da análise ANOVA, executados através do programa Microsoft Excel.

Tabela 2: Resumo ANOVA

\begin{tabular}{|c|c|c|c|c|c|c|}
\hline RESUMO & & & & & & \\
\hline Grupo & Contagem & Soma & Média & Variância & & \\
\hline Referência & 14 & 136,63 & 9,759285714 & 3,342499451 & & \\
\hline Argamassa - Espessura de $10 \mathrm{~mm}$ & 12 & 173,85 & 14,4875 & 0,927747727 & & \\
\hline Argamassa - Espessura de $15 \mathrm{~mm}$ & 15 & 245,621 & 16,37473333 & 4,92738321 & & \\
\hline Argamassa - Espessura de $20 \mathrm{~mm}$ & 15 & 193,25 & 12,88333333 & 7,695752381 & & \\
\hline \multicolumn{7}{|l|}{ ANOVA } \\
\hline Fonte da variação & $S Q$ & $g l$ & $M Q$ & $F$ & valor-P & F crítico \\
\hline Entre grupos & 336,4791749 & 3 & 112,159725 & 25,31584679 & $3,10121 \mathrm{E}-10$ & 2,782600423 \\
\hline Dentro dos grupos & 230,3816161 & 52 & 4,430415695 & & & \\
\hline Total & 566,860791 & 55 & & & & \\
\hline
\end{tabular}


MUNIZ, M.R.N; ET AL., VERIFICAÇÃO DA INFLUÊNCIA NA RESISTÊNCIA À TRAÇÃO NA FLEXÃO DE DIFERENTES ESPESSURAS DE REVESTIMENTO DE ARGAMASSA REFRATÁRIA EM PEÇAS DE CONCRETO REFORÇADO COM FIBRAS DE CARBONO SUBMETIDAS À TEMPERATURA DE $200^{\circ} \mathrm{C}$. $2^{\circ}$ Simpósio Paranaense de Patologia das Construções ( $2^{\circ} \mathrm{SPPC}$ ), artigo

\section{Considerações Finais} 2SPPC1032, pp. 380-391, 2017. DOI: 10.4322/2SPPC.2017.032

Após a análise dos resultados obtidos no programa experimental, é perceptível que os objetivos estabelecidos no começo deste trabalho foram atingidos, visto que foi analisada a influência na resistência à flexão da aplicação de diferentes espessuras de argamassa refratária em peças de concreto reforçadas com PRFC, quando as mesmas são submetidas à temperatura de $200^{\circ} \mathrm{C}$. Comparando os ensaios realizados, pôde-se observar:

A. Quanto ao ensaio:

I. Cada etapa foi realizada no mesmo dia para todos os corpos de prova prismáticos, minimizando qualquer tipo de influência na variação dos resultados.

II. O revestimento de argamassa refratária de $20 \mathrm{~mm}$ de espessura se desprendeu facilmente do corpo de prova no ato do rompimento.

B. Quanto aos resultados dos ensaios realizados com peças reforçadas com PRFC revestidas com argamassa refratária com espessuras de $10 \mathrm{~mm}, 15 \mathrm{~mm}$ e $20 \mathrm{~mm}$ submetidas à temperatura de $200^{\circ} \mathrm{C}$ :

I. Houve influência na resistência à tração na flexão das peças de concreto reforçadas com PRFC, quando submetidas à temperatura de $200^{\circ} \mathrm{C}$, corroborando parcialmente com a hipótese.

II. Realizando uma análise por ordem crescente dos resultados, 93\% das peças com espessura de $10 \mathrm{~mm}, 100 \%$ das peças com espessura de $15 \mathrm{~mm}$ e $33 \%$ das peças com espessuras de $20 \mathrm{~mm}$ obtiveram ganho de resistência quando comparadas com as peças de referência.

III. As peças de concreto revestidas com argamassa refratária com espessura de $10 \mathrm{~mm}$ obtiveram ganho médio na resistência, possuindo acréscimo de $63 \%$, e um coeficiente de variação de $13 \%$.

IV. As peças de concreto revestidas com argamassa refratária com espessura de $15 \mathrm{~mm}$ obtiveram ganho médio na resistência, possuindo acréscimo de $74 \% \mathrm{e}$ um coeficiente padrão de $14 \%$.

V. As peças de concreto revestidas com argamassa refratária com espessura de $20 \mathrm{~mm}$ obtiveram ganho médio na resistência, possuindo acréscimo de $37 \%$, e um coeficiente de variação de $22 \%$.

VI. A espessura de $15 \mathrm{~mm}$ apresentou maior ganho de resistência comparado com as espessuras de $10 \mathrm{~mm}$ e $20 \mathrm{~mm}$.

VII. Todas as peças de concreto revestidas com argamassa refratária com espessura de $15 \mathrm{~mm}$ obtiveram ganho médio na resistência comparado com a espessura de $10 \mathrm{~mm}$, possuindo acréscimo de 7\%, porém, conforme análise 
MUNIZ, M.R.N; ET AL., VERIFICAÇÃO DA INFLUÊNCIA NA RESISTÊNCIA À TRAÇÃO NA FLEXÃO DE DIFERENTES ESPESSURAS DE REVESTIMENTO DE ARGAMASSA REFRATÁRIA EM PEÇAS DE CONCRETO REFORÇADO COM FIBRAS DE CARBONO SUBMETIDAS À TEMPERATURA DE $200^{\circ} \mathrm{C}$. $2^{\circ}$ Simpósio Paranaense de Patologia das Construções ( $\left.2^{\circ} \mathrm{SPPC}\right)$, artigo 2SPPC1032, pp. 380-391, 2017. DOI: 10.4322/2SPPC.2017.032 de variância realizada, este acréscimo não é significativo, pois a diferença das médias entre os dois grupos é mínima.

VIII. Todas as peças de concreto revestidas com argamassa refratária com espessura de $15 \mathrm{~mm}$ obtiveram ganho médio na resistência comparado com a espessura de $20 \mathrm{~mm}$, possuindo acréscimo de $27 \%$.

IX. Todas as peças de concreto revestidas com argamassa refratária com espessura de $10 \mathrm{~mm}$ obtiveram ganho médio na resistência comparado com a espessura de $20 \mathrm{~mm}$, possuindo acréscimo de $19 \%$.

X. Acredita-se que o rompimento se deu por consequência do desprendimento da fibra de carbono, após a resina epoxídica atingir sua temperatura de transição vítrea, perdendo assim sua resistência e causando o rompimento do sistema.

\section{Agradecimentos}

Aos engenheiros Jose Eduardo Granato da Viapol LTDA e Maurício Bianchini da Supermix, pela contribuição dos materiais necessários para a viabilização do sistema de polímero e fibra de carbono e do concreto utilizados para a realização do programa experimental. Agradecemos ao engenheiro César Zanchi Daher por disponibilizar seu laboratório e equipamentos para a realização do ensaio.

\section{Referências}

[1] ABNT - ASSOCIAÇÃO BRASILEIRA DE NORMAS TÉCNICAS - NBR 5738 Concreto - Procedimento para moldagem e cura de corpos de prova. 2015.

[2] BEBER, A.J. Comportamento estrutural de vigas de concreto armado reforçadas com compósitos de fibra de carbono. Tese (Doutorado), Universidade Federal do Rio Grande do Sul. Porto Alegre, 2003.

[3] FERNANDES, M. R. F., Estudo das propriedades das argamassas refratárias úmidas com o tempo de estocagem. Escola de Engenharia da UFMG. Belo Horizonte, 2012.

[4] FORTES, A.S; PADARATZ, I.J.; BARROS, A.O.; FREIRE, I.F. Eficiência do reforço de CFRP em estruturas de concreto sob efeito térmico. V simpósio EPUSP sobre estruturas de concreto, 2003.

[5] MACHADO, A.P. Manual de reforço das estruturas de concreto armado com fibras de carbono. Belo Horizonte, 2002.

[6] SILVA, B, Análise da influência do tipo de cura na resistência a compressão de corpos de prova de concreto. Disponível em: <http://www.civil.ita.br/graduacao/tgs/resumos/2009/TGIEI003_Bruno_Silva.pdf >, Acesso 14/06/2016 as 02:30.

[7] ACI Committee 440 - Guide for the design and construction of externally bonded FRP systems for strengthening concrete structures, 118 p.2002. 